Products and Services In Practice is provided to readers using text and images from the manufacturer, supplier or distributor and does not imply endorsement by $B D J$ In Practice. Normal and prudent research should be exercised before purchase or use of any product mentioned.

Please send product and services news through to David Westgarth, BDJ In Practice via: David.Westgarth@bda.org

\section{The devil's in the detail}

Among the many benefits of the Cavex Cream alginate is its ability to replicate even the finest features with $5 \mu \mathrm{m}$ detail reproduction. Not only does this lead to accurate impressions for improved restorations and prostheses, but the patient will also appreciate the reduced need for retakes.

Cavex Cream is easy to mix and exhibits high tear strength and elasticity, making it ideal for multiple casting. Plus, it maintains dimensional stability for up to two days, giving sufficient time for impressions to be cast without any complications.

Available with normal or fast setting properties, Cavex Cream is distributed by J\&S Davis and can be ordered direct or from your normal supplier.

For more information on the industryleading products available from J\&S Davis, visit www.js-davis.co.uk, call 01438747344 or email jsdsales@js-davis. co.uk.

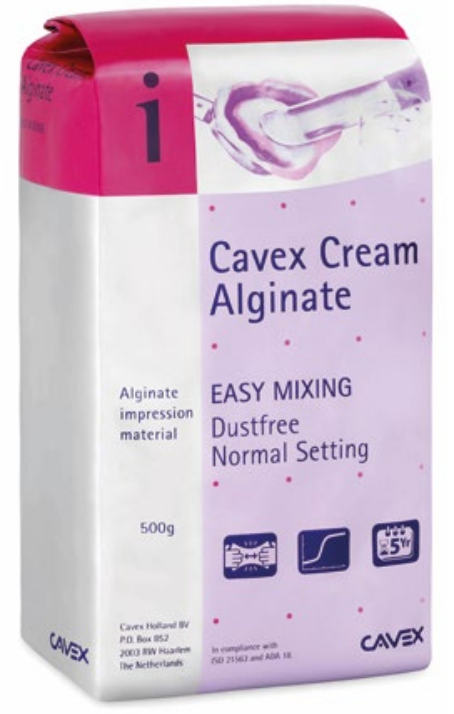

\title{
Simple solutions for minor TMJ complications
}

In some cases of minor TMJ complications, GDPs can offer simple yet effective solutions. For trismus, these might include botulinum toxin injections or easy-to-use devices like the OraStretch Press Rehab
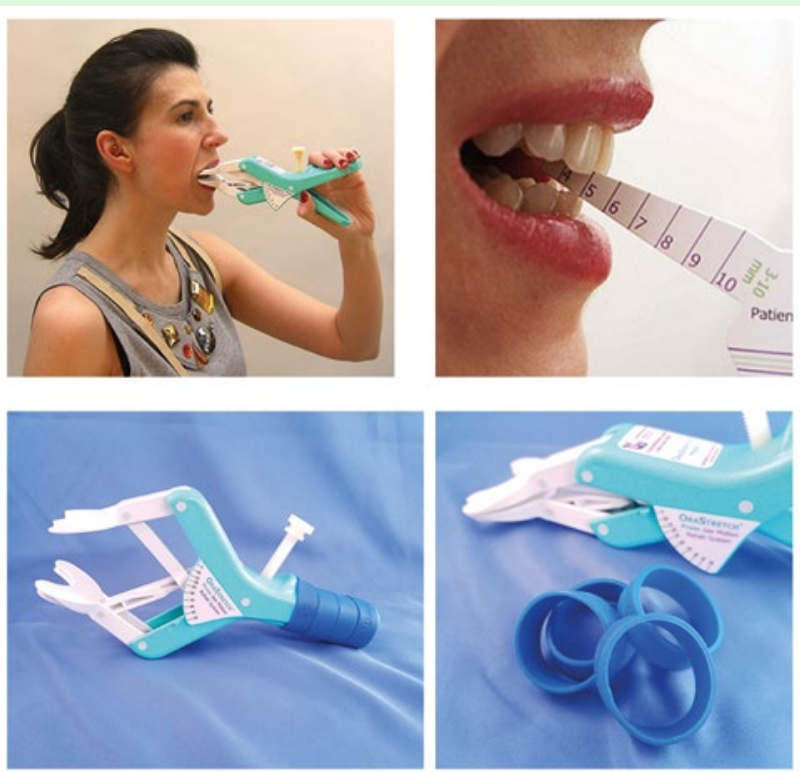

System from Incito Medtech.

The system uses passive motion to slowly and carefully stretch the jaw, joint and facial tissues. Designed to improve mobility and function, the device is handoperated and can be used by patients at home every day.

With an average of 1-2mm improvement in movement per week, the OraStretch offers GDPs a simple and effective solution for of their many patients with mild TMJ problems.

For more information please email rosiebh@ incitomedtech. co.uk or visit http:// incitomedtech.co.uk or call 07796058128.

\section{The easy choice}

In a crowded market, choosing the right oral health products can be confusing - for patients and practitioners supporting them.

TANDEX is adding international standard ISO and PHD (passage hole diameter) numbers to the packaging of its FLEXI interdental

brushes. This

makes it easier to

understand which

brush is suitable for each user

The ISO defines what

PHD interval the brush can be squeezed into without deformation. PHD is based on the number of filaments per $\mathrm{cm}$, nylon thickness per $\mathrm{mm}$ and how hard the brush is twined.

It's a simple system and new for 2020. Find out more today at www.tandex.dk. 